\title{
Optimization of building form and its fenestration in response to microclimate conditions of an urban area
}

\author{
Kavan Javanroodi ${ }^{1, *}$, Vahid M. Nikㄹ, and Yuchen Yang ${ }^{1}$ \\ ${ }^{1}$ Division of Building Technology, Department of Civil and Environmental Engineering, Chalmers University of Technology, \\ Gothenburg, Sweden (vahid.nik@ chalmers.se) \\ ${ }^{2}$ Division of Building Physics, Department of Building and Environmental Technology, Lund University, SE- 223 63, Lund, Sweden \\ (kavan.javanroodi@byggtek.lth.se, vahid.nik@byggtek.lth.se,nik.vahid.m@gmail.com) \\ ${ }^{3}$ Institute for Future Environments, Queensland University of Technology, Garden Point Campus, 2 George Street, Brisbane, QLD, \\ 4000, Australia (vahid.nik@qut.edu.au)DP Sciences, Editorial Department, 91944 Les Ulis Cedex A, France \\ ${ }^{2}$ EDP Sciences, Production Department, 91944 Les Ulis Cedex A, France
}

\begin{abstract}
Designing building form in urban areas is a complicated process that demands considering a high number of influencing parameters. On the other hand, there has been an increasing trend to design highly fenestrated building envelopes for office buildings to induce higher levels of natural lighting into the workspace. This paper presents a novel optimization framework to design high-performance building form and fenestration configuration considering the impacts of urban microclimate in typical and extreme weather conditions during a thirty-year period of climate data (2010-2039). In this regard, based on the introduced technique and algorithm, the annual energy demand and thermal comfort of over 8008 eligible form combinations with eight different fenestration configurations and seven different building orientation angels were analysed in a detailed urban area to find optimal design solutions in response to microclimate conditions. Results showed that adopting the framework, annual heating, and cooling demand can be reduced by $21 \%$ and $38 \%$ while maintaining thermal comfort by taking design-based decisions at the early stages of design.
\end{abstract}

\section{Introduction}

Cities are consuming about $70 \%$ of world energy [1], and with the current rapid urbanization rate, this share is expected to increase [2]. Buildings are accounted for about $48 \%$ of supplied energy for heating and cooling to achieve indoor thermal comfort [3]. There have been several attempts to reduce this share and demands from buildings in the two recent decades with a focus on designers [4]. The most recent approach is attempting to develop and use new computational power and associated tools to design the energy performance of buildings. In this approach, a common and wellacknowledged technique in the building design process is adopting an optimization algorithm in line with numerical simulation methods [5]. Considering several influencing parameters and constraints in the building design process, multi-objective optimization to solve complex design problems. Thus, dozens of optimization algorithms have been developed for multi-objective problems based on evolutionary algorithms [6]. These optimization algorithms have been adopted for the building design process in the early stages to construction process. In addition to regular programming platforms and tools such as Matlab [7]. The most common tools adopted and used by /for designers with more design-based interfaces are Grasshopper in Rhinoceros and Dynamo in Autodesk Revit with several practical plugins based on different simulation engines, focusing on different features and components of building such as building facade [8] or materials characteristics [9], glazing and shading [10] have been studied. Several other studies have focused on developing optimization frameworks to optimize the energy performance of buildings [11,12]. However, a comprehensive optimization framework with a back and forth process to finding optimal forms is still missing in the available literature.

The majority of the studies in the literature are only developed based in locally recorded weather data for typical years, such as different versions of Typical Meteorological Year (TMY) to represent long-term average climate conditions of a location [13]. These weather files fail to consider microclimate conditions. Moreover, these weather file cannot represent extreme weather conditions which can have a large impact on the peak loads. However, it is not feasible to design the overall form of a building based on microscale recorded or simulated data for each site due to expensive and time-consuming process [14]. Thus, an approach should be defined to couple microclimate simulation with

\footnotetext{
* Corresponding author: kavan.javanroodi@,chalmers.se
} 
design/optimization process of buildings at early stages of design.

This paper aims at defining this concept by optimizing the building form against typical and extreme weather conditions at microscale in a low-density urban area. This concept has been described in detail in the Methods section as well as the adopted optimization approach, influencing parameters and applied inputs for the whole process (see figure 1). The Pareto front plot of the developed optimization algorithm along with the geometrical characteristics of the top five best design options as the energy performance of four best solutions is also presented in the Results and discussion section.

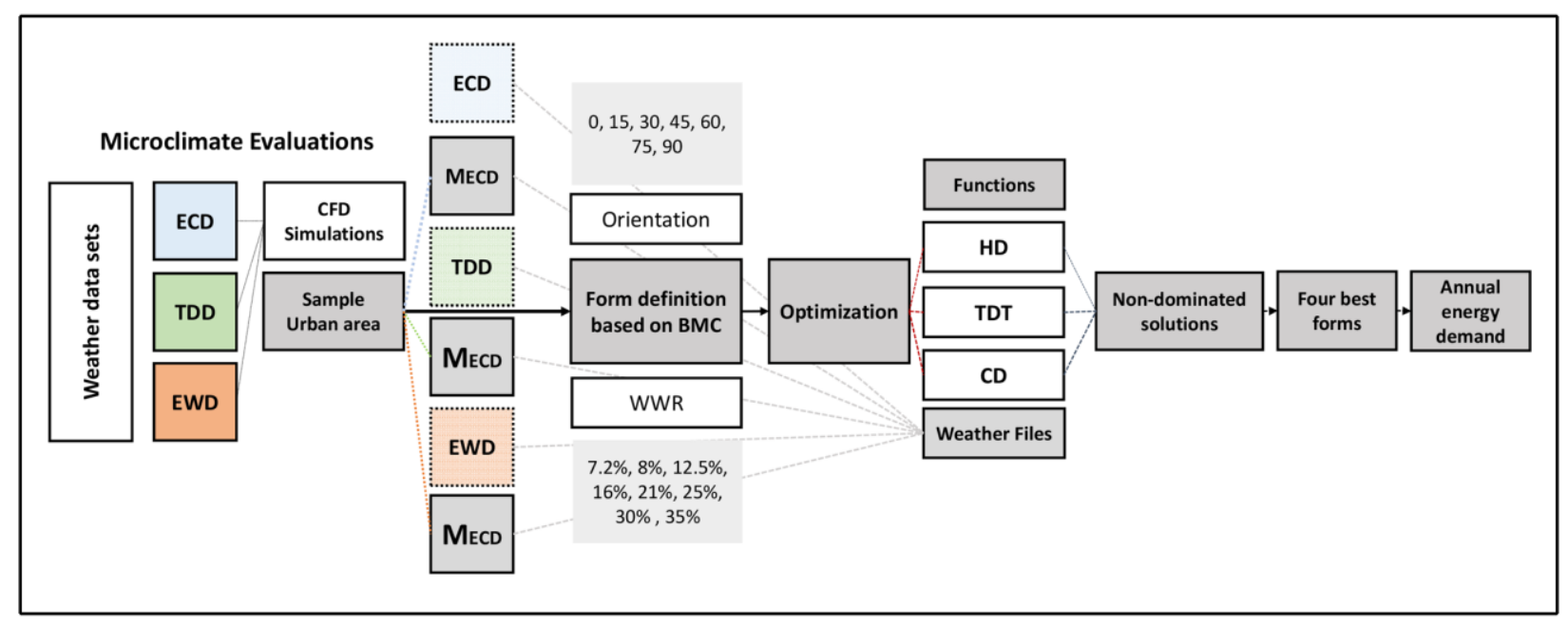

Fig. 1. Schematic framework of the study from microclimate evaluations to form optimizations.

\section{Methods}

\subsection{Microclimate evaluations}

\subsubsection{Reference weather data sets}

For reference weather data sets, three 24-hour continuous data were generated based on a method introduced by Nik [15] to synthesize typical and extreme weather files based on the outdoor temperature, considering six weather scenarios simulated by RCA4 regional climate model (RCM) with the spatial resolution of $12.5 \mathrm{~km}$ to be used in energy simulations. In this method, the representative and extreme months using Finkelstein-Schafer statistics are selected and verified for hygrothermal simulations [16]. Thus, these typical and extreme weather conditions are divided into three sets of typical, high and low air temperature are synthesized from 30-year period of weather data (20102039). There weather data are 'ECD' representing Extreme Cold Day, 'TDD' representing 'Typical Condition Day, and finally 'EWD' as 'Extreme Warm Day. These weather data (temperature wind speed, wind direction, solar radiation, and relative humidity) sets are used as inputs for boundary conditions in the numerical simulations.

\subsubsection{Sample urban area}

To evaluate microclimate condition, an urban area with low-density was developed based on a technique introduced by Javanroodi [17] namely 'BMC' or Building Modular Cells. Here, based on an $8 \times 8 \mathrm{~m}$ module, an urban area with eight buildings, one green space two streets (32 $\mathrm{m}$ width) and five canopies between adjacent buildings ( $8 \mathrm{~m}$ width) was generated. The sample urban area has two different constant building forms: a central cuboid building with $48 \mathrm{~m}$ height (each floor height is $4 \mathrm{~m}, 12$ floors) and seven semi-U form buildings- as one of the frequent urban forms in Athens- with different height distributions (Figure 2-a). The generated sample urban area is used for conducting CFD simulations and average simulated air temperature and wind speed were extracted to develop microclimate weather files (Section 1.1.3).

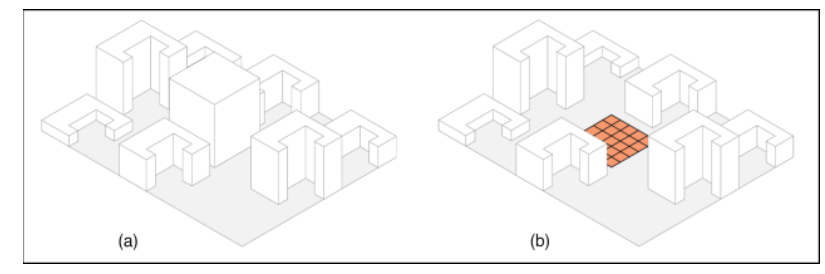

Fig. 2. (a) Sample urban area based on BMC technique, (b) Using the sample urban area as the platform for form optimization step.

\subsubsection{Numerical simulations}

The three 24-hour generated weather data (temperature wind speed, wind direction, solar radiation, and relative 
humidity) sets are used as inputs for boundary conditions in the numerical simulations. This resulted in 72 numerical simulations by means of CFD simulations. For CFD simulations, a developed method by Javanroodi was adopted using a verified Autodesk CFD and ANSYS Fluent coupled approach. Readers are referred to [18,19] for more explanation on the adopted method including boundary conditions, governing equations, and major inputs for CFD simulation. For computational domain, standards such as AIJ and COST [20,21] (in which distances from inlet and sides of the domain to model should not be less than $5 \mathrm{H}$ and at least $10 \mathrm{H}$ from behind the model) were adopted. In this study, lateral and top of the domain considered $10 \mathrm{H}$ and rear of the domain is $20 \mathrm{H}$, where $\mathrm{H}$ is the tallest model height which is $48 \mathrm{~m}$ in all case studies. Figure 3 shows the comparison mesoscale air temperature (out of generated wind data) and simulated air temperature (out of the results of CFD simulation in the sample urban area) with an hourly resolution. As it is clear, air temperature at microscale can be notably different compared to widely-used mesoscale weather file; which can result in different final energy demand simulation and calculations. The variation of the air temperature is a function of urban form and fluctuation of wind speed as can be seen in figure 4. In this figure CFD contours for two different hours with two different wind directions, reference wind speed and air temperature are presented. It is clear that the fluctuation of wind speed-affected as the interactions between building forms in the sample urban areachanges air temperature around and above the buildings. Based on the conducted numerical simulations, three new weather data sets are generated to represent microclimate conditions in the developed sample urban area. For example, $\mathrm{M}_{\mathrm{ECY}}$ means the microscale developed weather file out of numerical simulations using ECD data as inputs to represent microclimate conditions of the sample urban area.
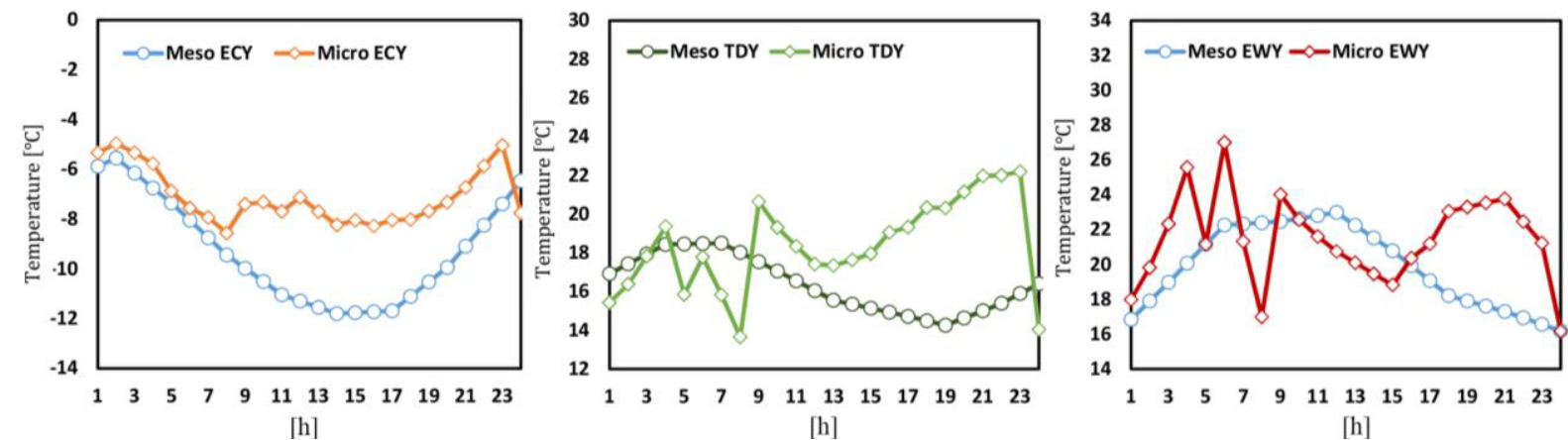

Fig.3. comparison between air temperature in mesoscale () and microscale (via CFD simulation) for three generated weather data.

\subsection{Form optimization}

Several design-based tools which are familiar for designers such as Rhinoceros and Grasshopper plugins (Diva-for-Rhino-Archsim, Ladybug tools and Octopus) and EnergyPlus has been adopted in this study. At the first phase, by the aid of an innovative GH algorithm, BMC technique defined, modelled and prepared for simulations. The geometry of eligible combinations was converted and exported into EnergyPlus by means of Archsim in the GH algorithm for thermal simulations. At the final phase, a generation-simulation-optimization loop is added to the $\mathrm{GH}$ algorithm, which hundreds of geometries are generated and simulated to optimize the final form of the reference building considering all the influencing parameters and indicators. In the developed multi-optimization algorithm, $\mathrm{WWR}_{\mathrm{s}}$ as the glazing ratio of the Southern surface elevation and building orientations as well as BMC technique form generator function work as genomes. in this regard, for glazing, eight different scenarios $\left(\mathrm{WWR}_{\mathrm{S}}=7.2 \%, 8 \%, 12.5 \%\right.$, $16 \%, 21 \%, 25 \%, 30 \%$ and $35 \%$ ) for the Southern surface elevation and for orientations seven different scenarios are designed $(\beta=0,15,30,45,60,75$ and 90). Three objective functions are defined to optimize heating demand, cooling demand and thermal discomfort time using three microscale weather files for three typical and extreme days $\left(\mathrm{M}_{\mathrm{ECD}}, \mathrm{M}_{\mathrm{TCD}}\right.$, and $\left.\mathrm{M}_{\mathrm{EWD}}\right)$. 

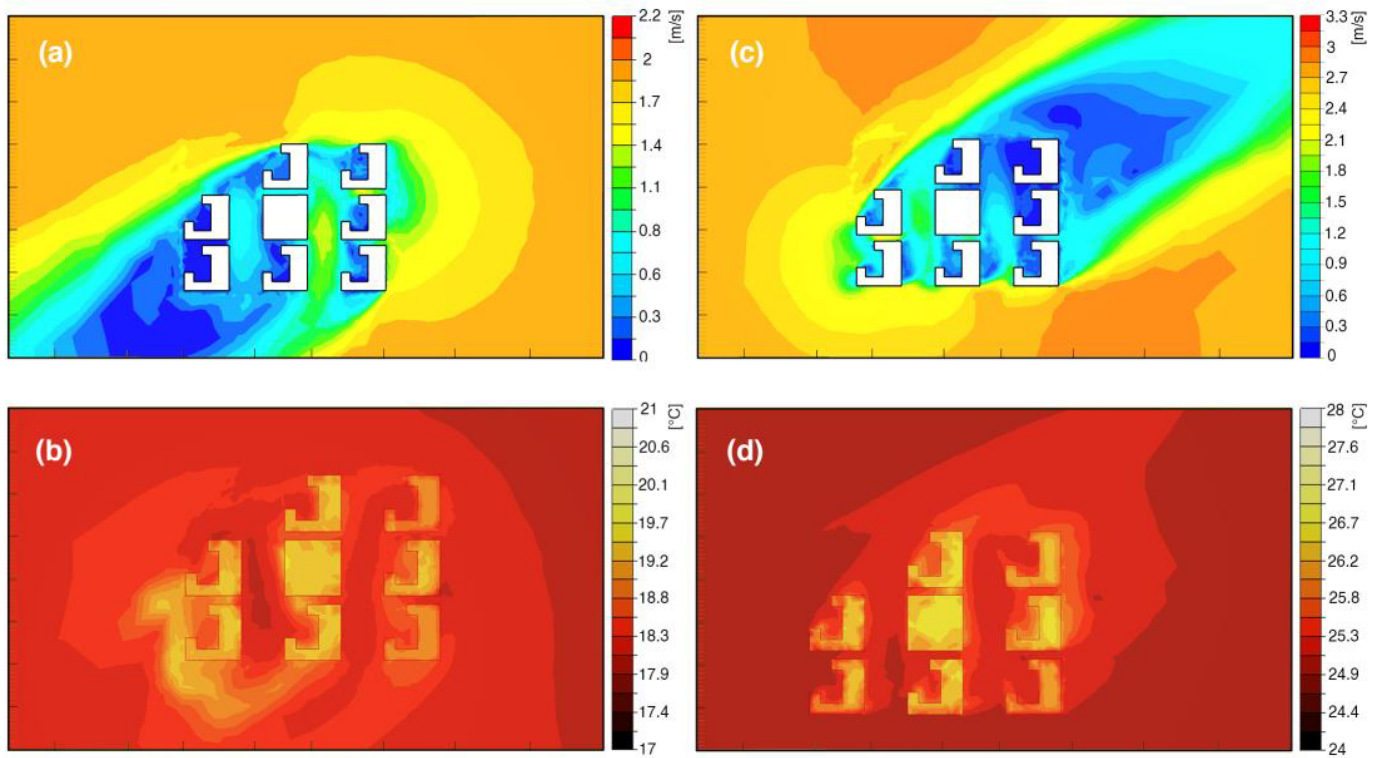

Fig.4. Two different wind velocity and air temperature CFD contours, (a) and (b) wind speed and air temperature with reference mesoscale wind direction, air temperature and wind speed of 240 degree, $18{ }^{\circ} \mathrm{C}$, and $2.1 \mathrm{~m} \cdot \mathrm{s}^{-1}$, respectively at $15 \mathrm{pm}$, input data out of TDD weather file; (c) and (d) wind speed and air temperature with reference mesoscale wind direction, air temperature and wind speed of 240 degree, $25^{\circ} \mathrm{C}$ and $3.2 \mathrm{~m} \cdot \mathrm{s}^{-1}$ respectively at $15 \mathrm{pm}$, input data out of EWD weather file.

\subsection{1 objective functions}

Three objective functions are defined for the purpose of the study to minimize heating and cooling demand while maintain thermal comfort. For heating demand, heating energy of generated form combinations from January.1 to March.31 and October.1 to Dcember.31 was simulated using EnergyPlus engine. Equation (1) shows defined objective function to minimize heating demand. Here $\mathrm{Q}_{\mathrm{H}}$ is simulated heating energy in each floor, $\mathrm{n}$ is the number of the floors (which is 12 here) and $\mathrm{A}$ is the total area of each floor.

$$
\mathrm{HD}=\frac{\sum_{i=1}^{n} Q_{H i}}{\sum_{i=1}^{n} A_{i}}
$$

For cooling demand, the cooling energy of the generated form combinations from April.1 to September.30 was simulated and optimized using equation (2), where $\mathrm{Q}_{\mathrm{C}}$ is simulated heating energy in each floor, $n$ is the number of the floors (which is 12 here) and $\mathrm{A}$ is the total area of each floor.

$$
\mathrm{CD}=\frac{\sum_{i=1}^{n} Q_{C i}}{\sum_{i=1}^{n} A_{i}}
$$

It is well known that a trade-off between energy demand and maintain thermal comfort is one the main challenges in designing buildings. An objective function was developed to maintain thermal comfort zone of the generated form combinations in each loop. To do so, Thermal Discomfort Time (TDT) introduced as an easyto-understand indicator which is the number of hours when the combination of humidity ratio and temperature is not in the comfort zone during summer ( 0.5 Clo.) and winter (1 Clo.). TDT shows the number of hours with thermal discomfort which should be minimized to have thermal comfort in the generated forms. Equation (3) shows the defined function for TDT based on ASHRAE 55 Adaptive model for Athens. Here $\mathrm{Ci}$ is based on simulated thermal discomfort time using EnergyPlus for each floor, $\mathrm{n}$ is 12 divided by 8760 .

$$
\mathrm{TDT}=\frac{\sum_{i=1}^{n} \mathrm{Ci}}{8760}
$$

\section{Results and discussions}

The multi-objective optimization with 100 populations, maximum 40 generations, mutation rate of 0.5 and crossover rate of 0.8 with SPEA-2 reduction was performed on a Core i7 computer (calculation time for the optimization problem was $4.2 \mathrm{~h}$ ). Figure 5-a shows a simplified sample to interpret the Pareto-Front of the optimization problem, and possible region for the nondominated solutions. The Pareto-Fronts of the optimization problem based on three defined objective functions is illustrated in Figure 5-b. 


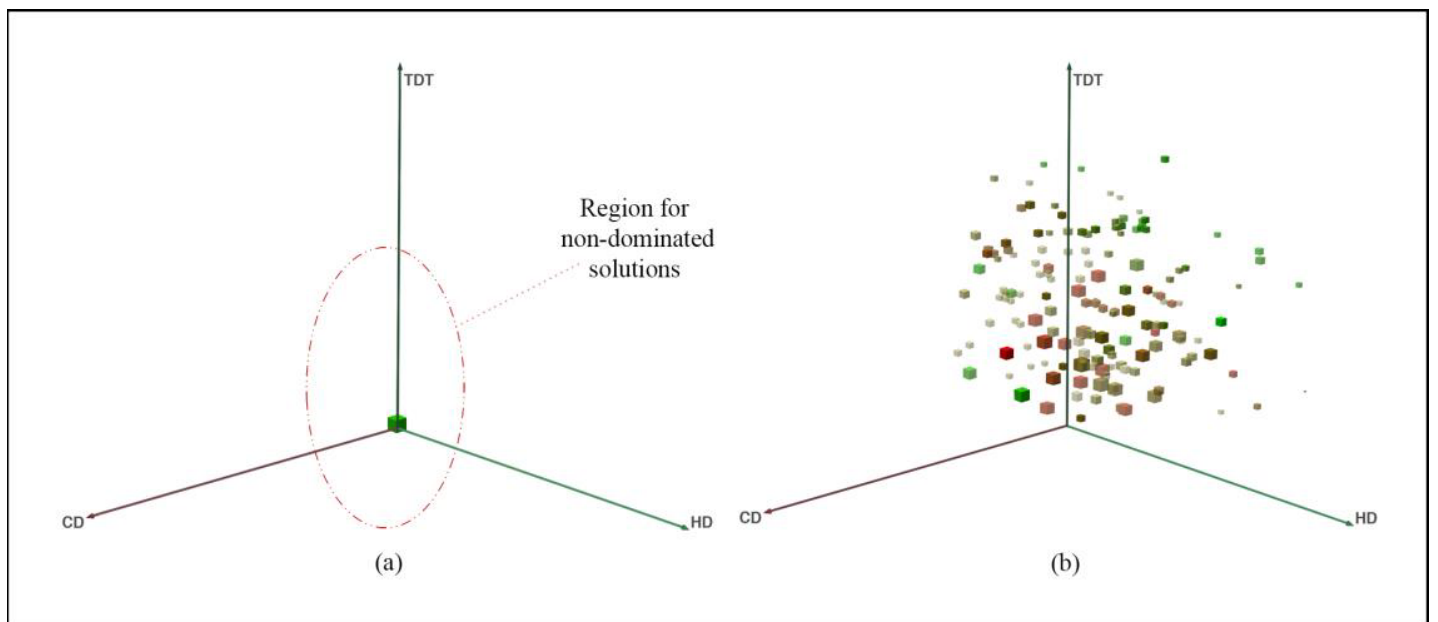

Fig.5. (a) a simplified sample to interpret the Pareto-Front of the optimization problem, and possible region for the nondominated solutions; (b) Pareto-Fronts of the optimization problem based on three defined objective functions

Figure 6 illustrates five best solutions out of nondominated design solutions in the sample urban area and Figure 7 and 8 present boxplots of annual heating and cooling demand for four best forms with their 3D visulation respectively. Average heating demand for three semi-courtyard forms are about $12 \mathrm{kWh}$; while this number is over $58.2 \mathrm{kWh}$ for the cuboid form in extreme cold conditions. In typical and extreme warm conditions this number is lower than $5 \mathrm{kWh}$; however, for the cuboid form is still close to extreme cold condition. The performance of semi-courtyard forms can be very important indicating a more robust performance during one year, a building with an efficient performance in extreme cold year and extreme warm year. It should be noted that peak heating load in all four cases is similar and about 55 to $59.8 \mathrm{kWh}$. On the other hand, cooling demand of the three selected semi-courtyard form is notably higher than the cuboid form. Here the orientation of the form can improve its performance where form No.62 with $8 \%$ WWR have a similar CD to cuboid form with less than $5 \mathrm{kWh}$ average cooling demand. This form has also the lowest peak cooling load compared to all non-dominated solutions. During extreme warm conditions, form No.37 have the best performance with $5.9 \mathrm{kWh}$ average cooling demand and $51.2 \mathrm{kWh}$ peak load.

As it is clear the majority of non-dominated cases have semi-courtyard forms; where about $41 \%$ of nondominated solutions have at least one empty cell as a courtyard form in an integrated plan. In terms of optimal heating demand design solutions more than $65 \%$ of best solutions have courtyard or semi-courtyard form; where $68 \%$ of which have set-backs to the northern side of the site. Moreover, $74 \%$ of non-dominated solutions have at least two or more empty cells in western and northern sides. Furthermore, $60 \%$ of best solutions have 15 degree clockwise site rotation and 20\% have 90-degree clockwise toward east which enables a larger part of the target building to face northern elevation with no surrounding buildings. Results also showed that $62 \%$ of the 51 non-dominated forms with optimal cooling demand have semi-courtyard forms, $21 \%$ have $\mathrm{L}$ or $\mathrm{U}$ forms and the rest or particular single forms from $\mathrm{T}$ form to distinct subtractive forms. A reason for the high frequency of courtyard or semi-courtyard forms with a compact shape is the higher temperature in the courtyard in winters $(0.9$ to $1.4 \mathrm{C})$ and respectively lower temperature in summers $(2.9$ to $3.8 \mathrm{C})$ compare to calculated temperature of the surrounding spaces in the urban area. The best WWR ratio on the Southern surface evaluation is $21 \%$ with over $54 \%$ of non-dominated solutions. It should be noted that semi-courtyard forms have higher surfaces exposed to South which result in a better performance in the hot seasons by natural ventilation. The analyses of numerical simulation indicate lower air temperature around Southern openings due to shading provided by surrounding buildings adjacent to the canopies. Another interesting fact is the frequency of empty cells in the western and southern sides of optimal solutions in the most of non-dominated solutions. Empty cells have a considerable impact on temperature variation around and inside adjacent building cells; a reason is higher external surface to gain solar radiation. The CFD contours provides proves for this phenomenon. 


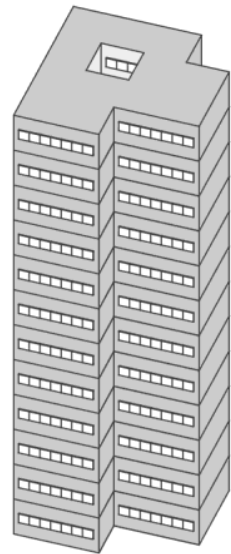

Form No.29 $W W R=21 \%$ $\mathrm{S}_{\mathrm{S}}=3840^{2} \mathrm{~m}$ $\beta=15$

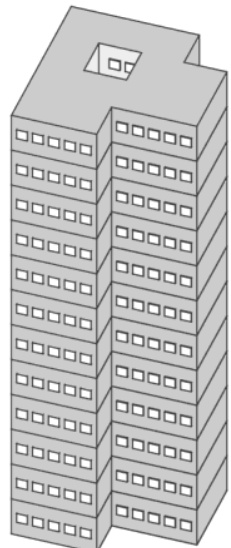

Form No.62
$\begin{gathered}W W R=8 \% \\ S\end{gathered}$
$S_{S}=3840^{2} m$
$\beta=0$

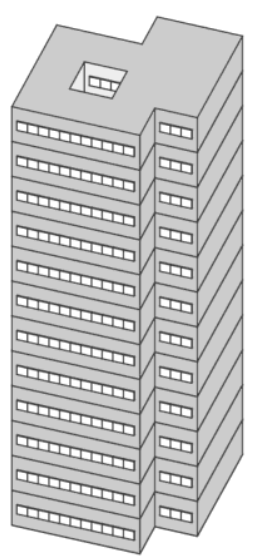

Form No.104

WWR $=21 \%$

$\mathrm{S}_{\mathrm{S}}=3840 \mathrm{~m}^{2}$

$\beta=15$

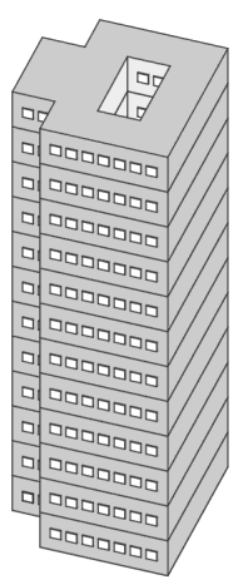

Form No.07

$W W R=7.2 \%$

$\mathrm{S}_{\mathrm{S}}=3840 \mathrm{~m}^{2}$

$\beta=30$

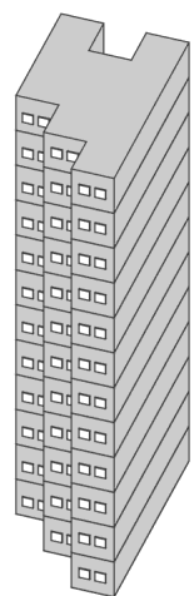

Form No.37

WWR $=12.5 \%$

$\mathrm{S}_{\mathrm{s}}=2304 \mathrm{~m}^{2}$

$\beta=15$

Fig.6. Five best forms out of fifty-one non-dominated solutions

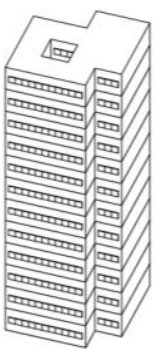

(a)

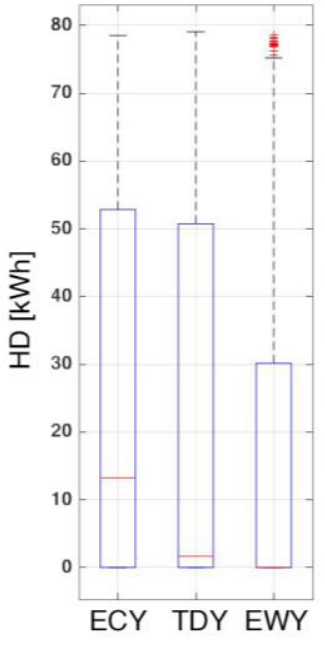

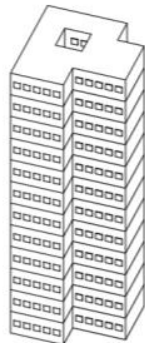

(b)

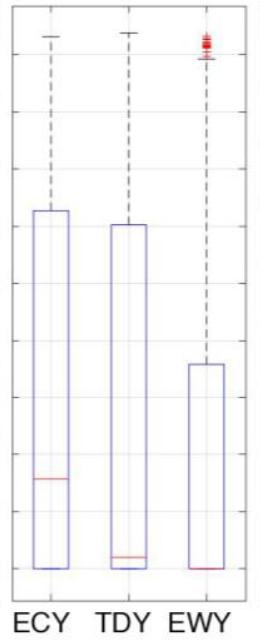

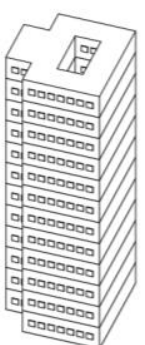

(c)

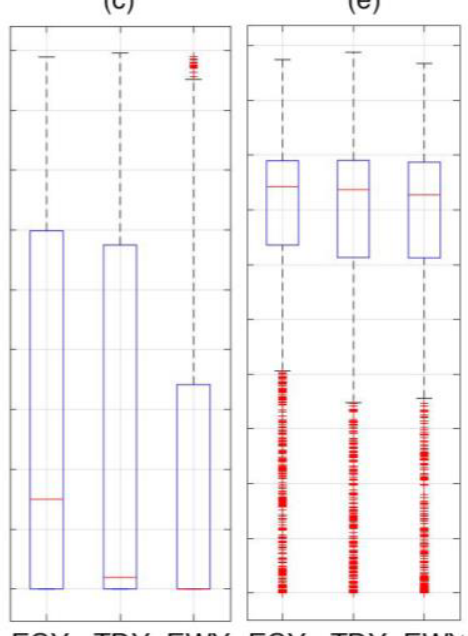

Fig.7. Boxplots of the annual HD (heating demand) of the four best cases using three generated mesoscale weather files (ECY, TDY, and EWY). (a) Form No.104, (b) Form No.29, (c) Form No.07, (d) Form No.37 


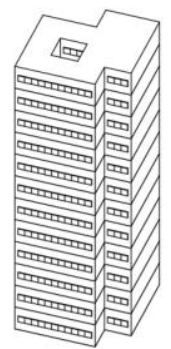

(a)

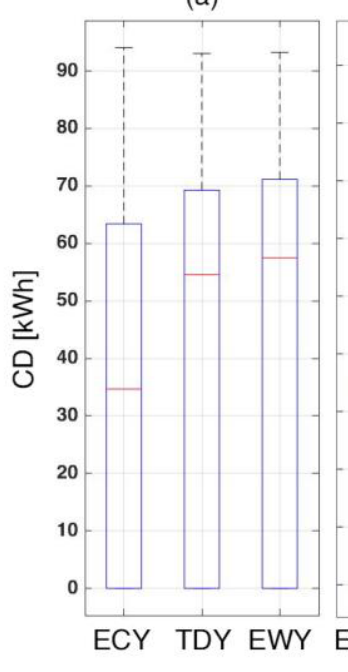

(b)

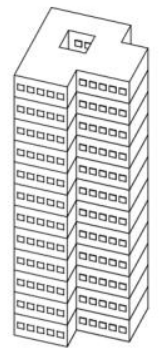

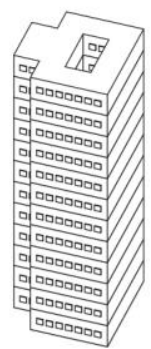

(c)

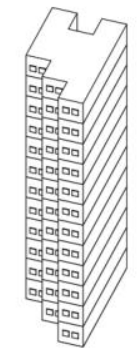

(e)

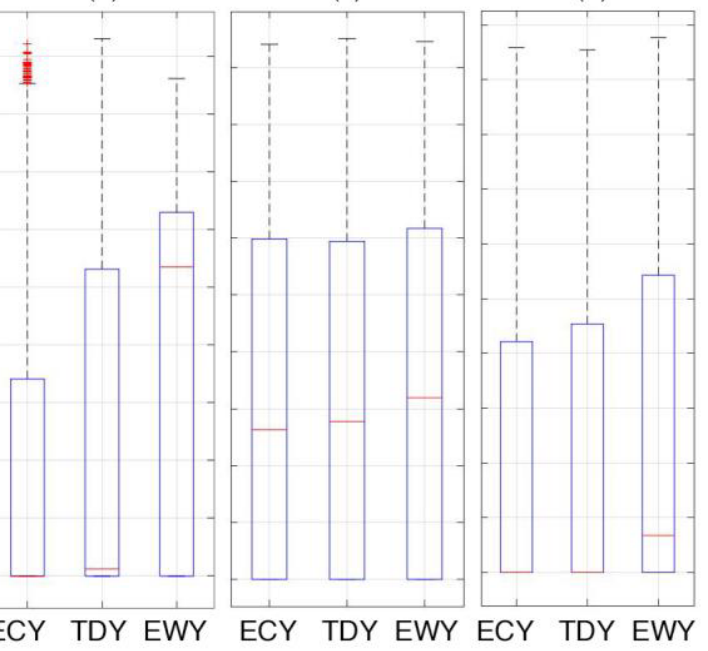

Fig.8. Boxplots of the annual CD (cooling demand) of the four best cases using three generated mesoscale weather files (ECY, TDY, and EWY). (a) Form No.104, (b) Form No.29, (c) Form No.07, (d) Form No.37

\section{Conclusions}

This study presented a multi-objective optimization framework in response to microclimate in typical and extreme weather conditions. The microclimate conditions were evaluated through 72 CFD simulation with an hourly time-step to generate three typical and extreme cold and warm daily weather file to optimise the form of a 12-floor building within a sample urban area hypothetically placed in the Athens city.

Three objective functions were defined to solve an optimization problem to find optimal solutions with minimum heating and cooling demand while maintaining thermal comfort conditions in the generated form combinations. Fifty-one non-dominated solutions were extracted from the optimization problem and four best solutions selected for more detailed evaluations. The main findings of this study can be summarized as:

- Forms with about $21 \%$ WWR on the Southern surface elevation showed the best overall performance during typical and extreme condtions. The other WWRs with high performance were also presented in the study.

- Semi-CY forms showed the best performance in both warm and cold seasons in extreme conditions.

- Forms with up to 15-degree clock-wise on the northern-southern axis (placing the form on NW/SE axis) showed the nest energy performance during studied weather conditions.
- Forms with high angles of rotation did not show a positive performance in terms of energy demand.

- Buildings with semi-courtyard forms with a compact shape has a higher temperature in the courtyards during winters $(0.9$ to $1.4 \mathrm{C})$ and respectively lower temperature in summers (2.9 to $3.8 \mathrm{C}$ ) compared to calculated temperature of the surrounding spaces in the sample urban area.

- Microclimate conditions increase average temperature of urban area in the coldest and warmest hours, with some expectations due to variations in the wind speed and wind direction.

This paper provided further evidence on the importance of considering microclimate conditions in designing building forms. Moreover, by taking low-cost decisions in the early design stages by designers, the energy performance of the buildings can be dramatically reduced. The developed framework and fast and lowcase method for considering microclimate conditions can enhance the quality of the form-finding process in the early design stages. It can also allow designers to take more well-informed decisions.

\section{References}

1. Fifth Assessment Report - Mitigation of Climate Change. Cambridge University Press; n.d. 
2. M. Brockerhoff, Nations U. World Urbanization Prospects: The 2018 Revision. Population and Development Review (2018).

3. R. Ruparathna, K. Hewage, R. Sadiq. Renewable and Sustainable Energy Reviews 53,1032-1045 (2016).

4. K. Javanroodi, VM Nik, M. Mahdavinejad, Sustainable Cities and Society 49, 101597 (2019).

5. A.-T. Nguyen, S. Reiter, P. Rigo, Applied Energy 113, 1043-1058 (2014).

6. K. Bamdad, ME. Cholette, L. Guan, J. Bell, Energy and Buildings 154, 404-414 (2017).

7. DWU Perera, D. Winkler, N.-O. Skeie, Applied Energy 171, 46-57 (2016).

8. Z. Zhou, C. Wang, X. Sun, F. Gao, W. Feng, G. Zillante, Journal of Cleaner Production 174, 413-423 (2018).

9. Y. Cascone, A. Capozzoli, M. Perino, Applied Energy 211, 929-953 (2018).

10. E. Fernández, B. Beckers, G. Besuievsky, A fast daylighting method to optimize opening configurations in building design. Energy and Buildings 125, 205-218 (2016).

11. X. Shi, Z. Tian, W. Chen, B. Si, X. Jin, Renewable and Sustainable Energy Reviews 65, 872-884 (2016).

12. A. Esmaeilzadeh, MR. Zakerzadeh, AY. Koma, Sustainable Cities and Society 43, 601-623 (2018).

13. S. Janjai, P. Deeyai, Applied Energy 86, 528537 (2009).

14. D. Mauree, E. Naboni, S. Coccolo, ATD: Perera, VM Nik, J.-L. Scartezzini, Renewable and Sustainable Energy Reviews 112, 733-746 (2019).

15. VM. Nik, Applied Energy 177, 204-226 (2016).

16. VM. Nik, Hygrothermal Simulations of Buildings Concerning Uncertainties of the Future Climate. (2012).

17. K. Javanroodi, M. Mahdavinejad, VM. Nik, Applied Energy 231, 714-746 (2018).

18. K. Javanroodi, VM. Nik, Interactions between extreme climate and urban morphology: Investigating the evolution of extreme wind speeds from mesoscale to microscale. Urban Climate 31, 100544 (2020).

19. K. Javanroodi, VM. Nik, Buildings 9, 198 (2019).

20. Y. Tominaga, A. Mochida, R. Yoshie, H. Kataoka, T. Nozu, M. Yoshikawa, et al., Journal of Wind Engineering and Industrial Aerodynamics 96, 1749-1761 (2008).

21. A. Mochida, Y. Tominaga, S. Murakami, R. Yoshie, T. Ishihara, R. Ooka, Wind and Structures 5, 227-244 (2002). 